\title{
O uso do Jogo Digital Minecraft para Estimular o Pensamento Computacional e a Aprendizagem Colaborativa no Ensino Fundamental I: Um Relato de Experiência
}

\author{
Genarde Macedo Trindade ${ }^{1,2}$, Felipe P. Fernandes ${ }^{1}$, Luiz Sérgio de O. Barbosa ${ }^{1,2}$, \\ Dayane Rosas de Souza ${ }^{1}$ \\ ${ }^{1}$ Centro de Estudos Superiores de Itacoatiara (CESIT) - Universidade do Estado do \\ Amazonas (UEA) - Itacoatiara - AM - Brasil \\ ${ }^{2}$ Mestrado em Tecnologias Emergentes em Educação (MTEE) - Miami University of \\ Science and Technology (MUST) - Boca Raton - FL - Estados Unidos \\ \{genardemacedo, dayanerosas\}@gmail.com \{fpf.lic17, lsergio\}@uea.edu.br
}

\begin{abstract}
This research presents the use of the Minecraft digital game in order to stimulate the computational thinking and collaborative learning of 4th grade students of Elementary School. To achieve the objective of the study, the adopted methodology is of qualitative and experimental character. The results of the experiment show satisfactory evidence regarding the use of the Minecraft game to employ computational thinking in problem solving, promoting the gain of skills in collaborative learning, such as: working the attention, concentration and interpersonal relationships of students.
\end{abstract}

Resumo. Esta pesquisa apresenta a utilização do jogo digital Minecraft com o objetivo de estimular o pensamento computacional e a aprendizagem colaborativa de alunos do $4^{\circ}$ ano do Ensino Fundamental I. Para atingir o objetivo do estudo, a metodologia adotada é de caráter qualitativa e experimental. Os resultados do experimento apresentam indicios satisfatórios quanto ao uso do jogo Minecraft para empregar o pensamento computacional na resolução de problemas, promovendo o ganho de habilidades na aprendizagem colaborativa, como: trabalhar a atenção, concentração $e$ relações interpessoais dos alunos.

\section{Introdução}

Os jogos digitais apresentam diversas possibilidades de interação e criação que exige do jogador competências, como: tomada de decisão, escolha de estratégias, colaboração por um objeto comum [Machado e Junior, 2019; Paiva e Tori, 2017]. Assim, é importante que haja a integração entre práticas pedagógicas desafiadoras e inovadoras para promover aprendizagens por situações-problema, permitindo que os alunos debatam coletivamente e criem soluções de maneira prática.

Nesse contexto, o pensamento computacional é a base para resolução de vários problemas no dia a dia nos mais diversos campos do conhecimento. Permitindo criar diferentes níveis de abstração e escolher os níveis adequados para se trabalhar, além de identificar e ver as relações entre cada um dos níveis [Wing, 2006; Santana e Martins, 
2017]. Assim, promover o pensamento computacional e a aprendizagem colaborativa torna-se uma estratégia viável para contribuir por meio do uso de jogos digitais.

Desta forma, este estudo apresenta a condução de um relato de experiência onde a principal motivação visou auxiliar no estímulo do pensamento computacional e na aprendizagem colaborativa com estudantes do ensino fundamental I. O estudo foi aplicado em ambiente real, com alunos de uma escola pública, usando uma abordagem construcionista de ensino, por meio do jogo digital Minecraft que possibilitou que os alunos aprendessem enquanto se divertiam. A escolha do jogo baseou-se no fato de que o mesmo permite que o "trabalho" dos alunos torne-se mais estimulador, dinâmico e divertido, pois há mistura de história (narrativas) com as atividades devido à mecânica que o jogo oferece, possibilitado atividades colaborativas entre os participantes.

\section{Fundamentação Teórica}

$\mathrm{Na}$ literatura existe estudos que propõe a utilização de diferentes jogos digitais para promover o estímulo do pensamento computacional e bem como da aprendizagem colaborativa [Paiva e Tori, 2017].

O Pensamento Computacional baseia-se na apropriação de saberes sobre os processos computacionais e como são executados, tanto por máquinas quanto pelo homem. Assim, está diretamente relacionado na maneira que o indivíduo consegue resolver ou interpretar problemas, ou seja, pensar computacionalmente para que possa construir/elaborar estratégias para a resolução de situações-problemas [Wing, 2006].

A aprendizagem colaborativa propõe o conjunto das seguintes condições, sendo: a promoção do autoconceito dos alunos, aumento da qualidade e da quantidade do feedback, desenvolvimento de materiais didáticos de qualidade que permitam uma integração eficaz no currículo, desenvolvimento de capacidades de autogestão dos alunos, resolução de problemas aliadas à capacidade de pensar criticamente, adequação dos fluxos de aprendizagem seguindo o ritmo dos alunos e aperfeiçoamento dos processos de avaliação [Amaro et. al, 2016].

O jogo digital Minecraft é classificado como open world, ou seja, um "mundo virtual aberto", onde o jogador pode "movimentar-se livremente" e usar a imaginação para desenvolver o ambiente do jogo [Souza, 2016]. O Minecraft possui cubos texturizados para permitir construções em um mundo regido por suas próprias leis. $\mathrm{O}$ jogo dispõe três formas de atuação para os jogadores, sendo: modo criativo, modo sobrevivência e modo aventura. Todos os modos dispõem de ferramentas que possibilitam criar e modificar o mundo virtual do jogador. A liberdade oferecida na construção do espaço virtual do jogador rompe com a linearidade oferecida em muitos jogos [Nebel et. al, 2016].

\subsection{Pensamento computacional}

Para Ferreira et al (2019), uma das principais características do pensamento computacional é possuir a estrutura com cinco dimensões centrais, que são: abstração, generalização, algoritmo, modularidade e decomposição. Essas dimensões contribuem para avaliar o nível do pensamento computacional adquirido pelos indivíduos, já que na sociedade contemporânea é fundamental apropriar-se de tais habilidades. 
Wing (2006) apresenta os conceitos das dimensões centrais do pensamento computacional: (a) abstração; (b) generalização; (c) modularidade; (d) algoritmo; e (e) decomposição.

a) Abstração: Tem grande importância na avaliação do pensamento computacional, pois permite dividir um problema em partes menores para facilitar a resolução. A abstração consiste na análise das qualidades dos objetos a serem estudados, como por exemplo, quando ouvimos o som de um instrumento, ou observarmos movimento de um carro, pois, extraímos as ações as ações (ouvir e observar) dos objetos, essa habilidade cognitiva é uma forma de abstração.

b) Generalização: É o resultado do processo de abstração da solução de algo, onde o número de passos, variáveis e constantes é adotado como métricas para facilitar a definição do caso a ser solucionado, pois o processo de generalização é decorrente do processo de abstração, partindo da caracterização de um determinado contexto.

c) Modularidade: Surge da maneira que um produto é fisicamente dividido em componentes. Uma característica da modularidade é o grau em que as interações entre os componentes físicos estão estabelecidas na formação de um produto. A divisão em módulos favorece o trabalho nas partes que interagem, formando um produto final.

d) Algoritmo: É um conjunto de operações lógicas, onde a execução resolve um problema por meio de um número finito de operações. Também, pode ser traduzido e executado em programas de computador através de alguma linguagem de programação.

e) Decomposição: Está relacionada com a separação de quantidades em unidades menores para chegar ao resultado final. A decomposição na Matemática e na Computação trabalham na mesma linha, sendo a divisão de um problema para trabalhar as partes menores e do mesmo tamanho.

\subsection{Aprendizagem colaborativa}

A aprendizagem colaborativa é proposta por um sistema de múltiplas interações entre os personagens do cenário escolar, não só nas interações professor e aluno ou entre alunos, mas também entre professores e entre a comunidade por meio das tecnologias. Esta relação prepara os novos aprendizes para o mundo do trabalho em constante transformação. Neste novo contexto educacional, o professor deixa o estado de detentor do conhecimento e passa a ser um mediador, podendo planejar, organizar e executar aprendizagens que estimulem e valorizem as ideias e concepções dos alunos. Dessa forma, a sala de aula passa a ser um laboratório que promove o desenvolvimento e a apropriação de novas habilidades dos aprendizes [Romanó, 2003].

A aprendizagem colaborativa permite que sejam trabalhados com os diferentes agentes escolares tópicos referentes ao respeito e a compreensão das diferenças pessoais. Além disso, a aprendizagem colaborativa pode ser utilizada em sala de aula ou em ambiente virtual, empregando recursos tecnológicos na obtenção do conhecimento [Fragelli, 2019].

\subsection{Construcionismo: aprender fazendo}

O construcionismo caracteriza-se pelo conceito de aprendizagem fundamentada na construção do conhecimento permanente, pois o estudante constrói a partir do ato de fazer. Isso não significa que, o estudante irá construir qualquer "coisa", e sim algo que 
promova motivação [Raabe, 2018]. Seymour Papert materializou suas ideias da utilização da linguagem LOGO, que proporciona aos aprendizes construir conhecimentos matemáticos no ato de "pensar matematicamente". Uma forma de promover o movimento maker na educação, onde os estudantes são os inventores do próprio conhecimento ao invés de serem ensinados [Blikstein, 2016].

Assim, analisa-se a importância do ato de construir e a forma que se manifesta na abordagem construcionista. Para isso, existe duas características especificas, sendo: (1) O aprendiz constrói alguma coisa (coloca a mão na massa); e (2) O aprendiz constrói "coisas" que despertam sua motivação e o envolvimento torna a aprendizagem mais significativa [Raabe, 2018].

\section{Trabalhos Correlatos}

Nesta seção são apresentados três trabalhos correlatos, os quais estão relacionados ao uso de jogos digitais no contexto escolar que serviram como suporte para a realização desta pesquisa, sendo: Paiva e Tori (2017); Santana e Martins (2017) e Dias e Rosalem (2014).

No trabalho de Paiva e Tori (2017), teve como principal objetivo mapear alguns dos processos cognitivos envolvidos na aprendizagem baseada em jogos, discutir como tais processos podem atuar de forma integrada ao conteúdo pedagógico, além de apontar benefícios, desafios e exemplos do uso de jogos digitais não educacionais no aprendizado por meio do jogo Minecraft. Os resultados apresentados permitiram fornecer informações ao educador, a fim de contextualizar o conteúdo didático a partir dos processos indicados por meio das informações adquiridas. Observou-se ainda, que existem metodologias específicas para uso do aprendizado baseado em jogos digitais onde o docente deve conhecer profundamente o conteúdo abordado.

O estudo de Santana e Martins (2017), tinha como objetivo o desenvolvimento de uma modificação (MOD) do jogo Minecraft para estimular o pensamento computacional em estudantes do ensino médio de forma construcionista. O MOD desenvolvido é um robô que pode ser programado pelo estudante seguindo uma linguagem de blocos de instrução parecida como o Scratch e o Blockly. Para validar o desenvolvimento do MOD foi definida uma rotina de testes para analisar todos os requisitos das modificações.

Na pesquisa de Dias e Rosalem (2014), o trabalho acompanhou e analisou de forma qualitativa o processo de ensino e aprendizagem de Ciências em um ambiente lúdico para os alunos do Ensino Fundamental II, por meio da utilização do jogo digital Minecraft, liderado por participantes do Programa Institucional de Bolsa de Iniciação à Docência (Pibid). O projeto ocorreu em uma escola pública estadual da cidade de Diadema, no estado de São de Paulo. Durante o período de aplicação do MinecraftEdu, os estudantes construíram dentro da plataforma uma célula eucariótica. Assim, o estudo utilizando o Minecraft atingiu seu objetivo, que era gerar um maior desenvolvimento social, lógico e criativo dos estudantes.

$\mathrm{Na}$ literatura existe diversos trabalhos que propõem a utilização de jogos digitais para promover o pensamento computacional. Observa-se assim, que muitos estudos já utilizaram o jogo digital Minecraft e que este pode ser empregado no contexto educacional. Entretanto, ainda não há estudos que trabalhe o pensamento computacional 
IX Congresso Brasileiro de Informática na Educação (CBIE 2020)

Anais do XXVI Workshop de Informática na Escola (WIE 2020)

e a aprendizagem colaborativa com alunos do ensino fundamental I, bem como analisar os impactos por meio do uso dessa ferramenta.

\section{Procedimentos Metodológicos}

A metodologia aplicada no estudo é adaptada parcialmente do trabalho de Souza et al., (2018) de caráter qualitativo e experimental com utilização de estudo de caso, onde fatores positivos e negativos são analisados. Assim, a metodologia possui quatro etapas, sendo: (1) Revisão da Literatura; (2) Planejamento do Estudo; (3) Execução do Estudo; e (4) Análise dos Resultados. A Figura 1 apresenta a visão geral da metodologia.

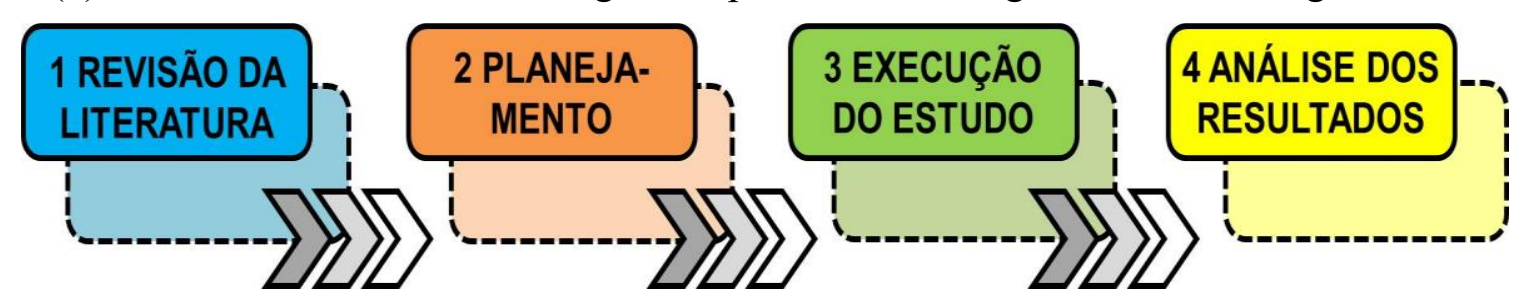

Figura 1. Visão geral da metodologia adotada na pesquisa, adaptada parcialmente do trabalho de Souza et al., (2018)

(1) Revisão da Literatura: Nessa etapa da metodológica, buscou-se trabalhos relacionados ao pensamento computacional, aprendizagem colaborativa, sobre o jogo digital Minecraft e bem como a empregabilidade de jogos na educação. A busca foi realizada em anais dos principais eventos científicos nacionais na área de informática na educação e o Google Scholar, que serviram para fundamentar o estudo.

(2) Planejamento do Estudo: Realizou-se a construção do cronograma com as atividades estabelecidas como essenciais para a execução do trabalho. Dentre elas estão: (a) Definição do local para realização do estudo; (b) Autorização para participação dos alunos constituídas em duas etapas, na primeira etapa realizou-se uma reunião com a coordenação pedagógica da instituição com o intuito de apresentar o estudo e definir os participantes, a seleção dos alunos foi realizada pela instituição onde aplicou-se o experimento, onde o critério para participar do estudo era que esse aluno residisse próximo da escola, visto que, a pesquisa seria executada no contraturno, na segunda etapa realizou-se uma reunião com os pais dos alunos selecionados; (c) Definição do tempo de duração do estudo, sendo definido dois bimestres de aplicação de atividades; d) Organização e elaboração das Tarefas/Desafios, ressaltando que as atividades iriam favorecer o trabalho coletivo; e) Organização dos Tablets para utilização no estudo, sendo 17 dispositivos com o jogo digital Minecraft instalado, essa quantidade favoreceu a utilização individual dos dispositivos com alunos; f) Caracterização do participante, documento elaborado para analisar e construir os perfis dos alunos que participaram do estudo; g) Elaboração do questionário pós-teste, com o objetivo de avaliar o processo de interação com o jogo Minecraft, o pensamento computacional e a aprendizagem colaborativa; h) Estudo de observação, que consistiu em analisar visualmente o processo de interação dos alunos com o jogo, o relacionamento interpessoal e a empregabilidade dos conceitos do pensamento computacional. Por meio do estudo de observação foi possível solidificar os dados coletados nos questionários pós-teste.

(3) Execução do Estudo: Realizou-se o estudo com 14 alunos com idade entre nove e dez anos que estavam cursando o $4^{\circ}$ ano do Ensino Fundamental I. A execução do estudo aconteceu nos dias de terça-feira e quinta-feira com duração de três horas 
cada encontro. Em seguida, realizou-se uma reunião com os responsáveis dos alunos que iriam participar do estudo para a assinatura do Termo Consentimento de Livre Esclarecido (TCLE).

Em seguida, deu-se início às atividades com os alunos. Para isto, primeiramente aplicou-se o Formulário de Caracterização do Participante para que fossem montados os perfis dos participantes em relação à utilização do jogo Minecraft, sobre tecnologia e em relação ao trabalho em equipe, com o intuito de analisar a evolução dos alunos durante o estudo. Depois, deu-se continuidade nas atividades que foram contextualizadas levando em consideração o pensamento computacional e a aprendizagem colaborativa. A seguir são apresentados os três módulos que compuseram o período de atividade, sendo:

a) Módulo 1 - Introdução ao pensamento computacional: Trabalhou-se com atividades estratégicas com a utilização do quadro branco e pincel a fim de permitir a compreensão dos conceitos básicos sobre o pensamento computacional, como, abstração, algoritmo e decomposição. A Figura 2 mostra registros de atividades realizadas no primeiro módulo do experimento.
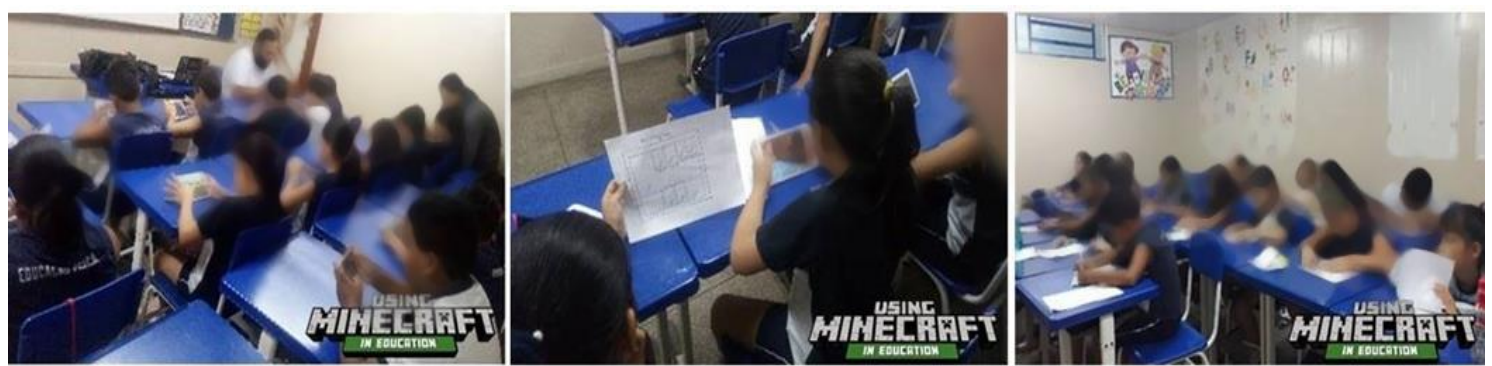

Figura 2. Realização de atividades Módulo 1 - Fonte: dos autores

b) Módulo 2 - Introdução ao jogo Minecraft: Apresentou-se o jogo para os alunos (na versão mobile), o objetivo desse módulo era explorar as funções do jogo, a fim de configurar para os participantes no modo criativo. Assim, criou-se uma rede para que os alunos pudessem trabalhar de forma colaborativa. Questões sobre trabalho em equipe (aprendizagem colaborativa) foram praticadas, como por exemplo, a construção de uma pequena vila de camponeses. A Figura 3 mostra registros de atividades realizadas com o uso do jogo.
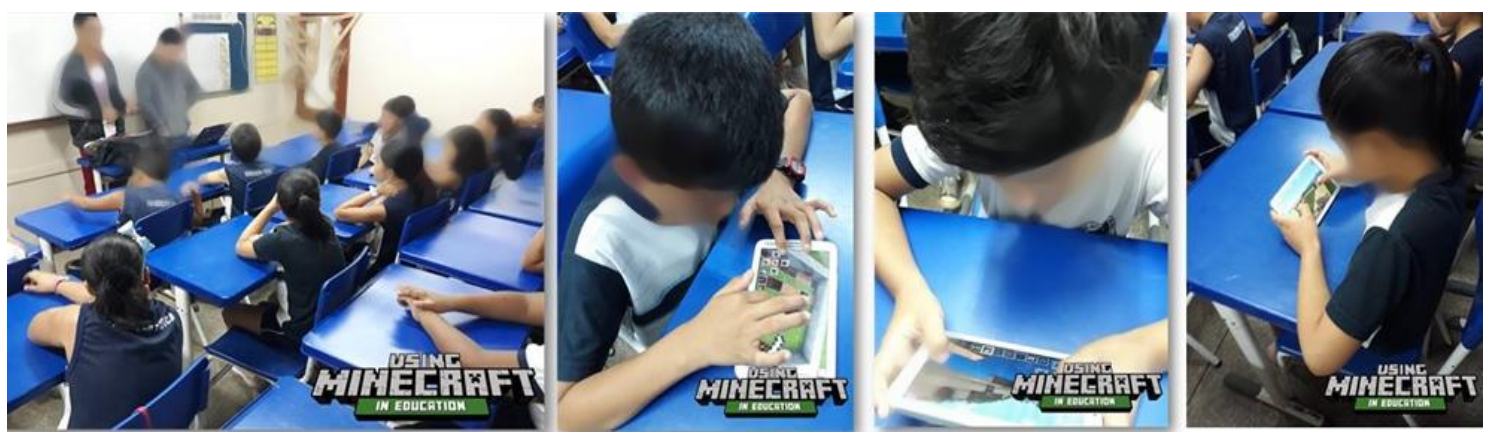

Figura 3. Realização de atividades on-line (em grupo) no Minecraft referente ao Módulo 2 - Fonte: dos autores

c) Módulo 3 - Atividades/Desafios: Solicitou-se a realização de atividades que necessitavam utilizar o pensamento computacional como estratégia para a resolução dos 
problemas e a aprendizagem colaborativa, a fim de permitir o engajamento dos alunos na execução das atividades. Dessa forma, a situação-problema trabalhada nas atividades/desafios com os alunos era a seguinte: A escola onde eles estudam passou por um sério problema na estrutura física e teve de ser demolida. Porém os alunos terão a oportunidade de reconstruir a escola de maneira coletiva no mundo virtual do jogo digital Minecraft e depois poderão exportar o projeto para uma empresa de construção que realizará a obra de maneira real. Assim, jogo Minecraft foi utilizado pelos alunos durantes o estudo para a construção segura da escola, como por exemplo a utilização dos blocos que são utilizados em obras como concreto, areia, tijolo, madeira e outros que fazem parte do jogo e podem ser empregados em construções reais. A Figura 4 apresenta os registros do produto final das atividades/desafios realizadas no Módulo 3 pelos participantes.
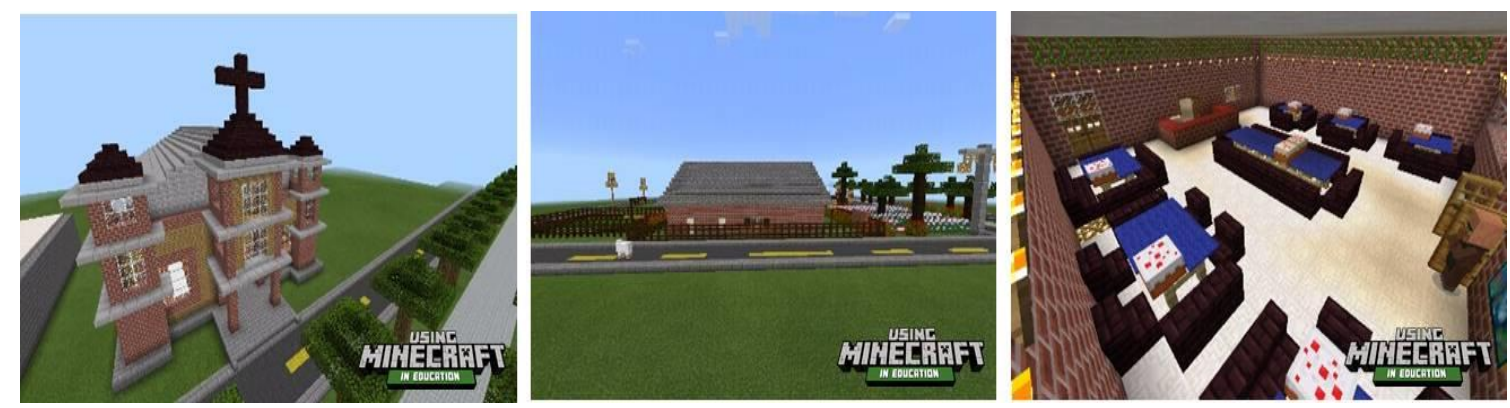

Figura 4. Cenário virtual construído durante o Módulo 3 - Fonte: dos autores

Durante o estudo de observação nas atividades executadas no Módulo 3, observou-se um ambiente de debate entre os participantes e trabalho em equipe, onde os alunos apresentaram dois fatores importantes no processo de aprendizagem, sendo, atenção e concentração. Notou-se ainda, que os alunos executavam as atividades com muito entusiasmo e sempre mencionavam palavras de satisfação com a utilização do jogo e pelo avanço das atividades, tais como: Comentário 1 "Muito bom estudar no Minecraft!"; comentário 2 "Nossa equipe conseguiu, estamos felizes!"; e comentário 3 "estou adorando usar o Minecraft".

\section{Resultados e Discussões}

$\mathrm{Na}$ quarta etapa do estudo, foram obtidos por meio da aplicação do questionário pósteste que ressaltava a assimilação dos alunos sobre os principais pontos do estudo. $\mathrm{O}$ questionário pós-teste era formado por quinze perguntas, sendo cinco sobre o Minecraft, cinco sobre pensamento computacional e cinco sobre o trabalho em equipe (aprendizagem colaborativa), tendo como alternativas para resposta uma escala com as opções: Ruim, regular, bom e ótimo. As Tabelas 1, 2 e 3 apresentam as questões e os respectivos resultados.

Tabela 1. Resultados das questões sobre o jogo Minecraft

\begin{tabular}{c|l|c|c|c|c}
\hline \multicolumn{1}{|c|}{ Questões } & Ruim & Regular & Bom & Ótimo \\
\hline Q01 & $\begin{array}{l}\text { O que você achou sobre utilizar o } \\
\text { Minecraft nas atividades? }\end{array}$ & - & - & - & $\begin{array}{c}100 \% \\
(14 \text { alunos })\end{array}$ \\
\hline Q02 & $\begin{array}{l}\text { Você considera o Minecraft um } \\
\text { jogo fácil de jogar? }\end{array}$ & - & - & - & $\begin{array}{c}100 \% \\
(14 \text { alunos })\end{array}$ \\
\hline
\end{tabular}




\begin{tabular}{c|l|c|c|c|c}
\hline Q03 & $\begin{array}{l}\text { Como você avalia o seu } \\
\text { desempenho no Minecraft e na } \\
\text { realização atividades? }\end{array}$ & - & - & $\begin{array}{c}28,5 \% \\
(04 \text { alunos })\end{array}$ & $\begin{array}{c}71,5 \% \\
(10 \text { alunos })\end{array}$ \\
\hline Q04 & $\begin{array}{l}\text { Como foi sua experiência jogando } \\
\text { Minecraft? }\end{array}$ & - & - & - & $\begin{array}{c}100 \% \\
(14 \text { alunos })\end{array}$ \\
\hline Q05 & $\begin{array}{l}\text { O que você acha em estudar } \\
\text { jogando Minecraft? }\end{array}$ & - & - & - & $\begin{array}{c}100 \% \\
(14 \text { alunos })\end{array}$ \\
\hline
\end{tabular}

A Tabela 1 sobre o jogo digital Minecraft, os alunos demostraram bastante facilidade de responder as questões. Dessa forma, Q01, Q02, Q04 e Q05 alcançaram $100 \%$ na opção "ótimo". A Q03 foi à questão que apresentou o resultado dividido entre duas opções, $28,5 \%$ na opção "bom" e 71,5\% na opção "ótimo", a mesma abordava o desempenho individual no jogo e na realização das atividades. A seguir, na Tabela 2 são apresentados os resultados referentes aos conceitos do pensamento computacional (abstração, algoritmo e decomposição) contidos nas atividades/desafios.

Tabela 2. Resultados das questões sobre o pensamento computacional

\begin{tabular}{|c|c|c|c|c|c|}
\hline $\mathbf{N}^{\circ}$ & Questões & Ruim & Regular & Bom & Ótimo \\
\hline Q06 & $\begin{array}{l}\text { Como você avalia a sua } \\
\text { interpretação } \\
\text { atividades/desafios? (Abstração) }\end{array}$ & - & - & - & $\begin{array}{c}100 \% \\
\text { (14 alunos) }\end{array}$ \\
\hline Q07 & $\begin{array}{l}\text { Como você avalia a divisão dos } \\
\text { problemas pela sua equipe? } \\
\text { (Decomposição) }\end{array}$ & - & - & - & $\begin{array}{c}100 \% \\
\text { (14 alunos) }\end{array}$ \\
\hline Q08 & $\begin{array}{l}\text { Como você avalia a execução das } \\
\text { atividades para a resolução dos } \\
\text { desafios? (Algoritmo) }\end{array}$ & - & - & $\begin{array}{c}28,5 \% \\
\text { (04 alunos) }\end{array}$ & $\begin{array}{c}71,5 \% \\
\text { (10 alunos) }\end{array}$ \\
\hline Q09 & $\begin{array}{l}\text { Como você conseguiu resolver os } \\
\text { problemas que ficaram em sua } \\
\text { responsabilidade? (Algoritmo) }\end{array}$ & - & - & $\begin{array}{c}28,5 \% \\
\text { (04 alunos) }\end{array}$ & $\begin{array}{c}71,5 \%(10 \\
\text { alunos) }\end{array}$ \\
\hline Q10 & $\begin{array}{l}\text { O que você acha sobre dividir } \\
\text { grandes problemas em menores? } \\
\text { (Decomposição) }\end{array}$ & - & - & - & $\begin{array}{c}100 \% \\
\text { (14 alunos) }\end{array}$ \\
\hline
\end{tabular}

Nota-se que somente Q06, Q07 e Q10 obtiveram 100\% na opção “ótimo", as questões abordavam os conceitos do pensamento computacional relacionados à abstração e decomposição. Já Q08 e Q09, questões ressaltavam o conceito de algoritmo, apresentou o resultado dividido entre duas opções, 28,5\% na opção "bom" e 71,5\% na opção "ótimo". Acredita-se que o resultado transparece a dificuldade que os alunos apresentaram em construir algo com um fluxo determinado de ações. Em seguida, apresenta-se a Tabela 3 com os resultados sobre o trabalho em equipe (aprendizagem colaborativa) que foram empregadas durante a realização das atividades/desafios.

Tabela 3. Resultados das questões sobre aprendizagem colaborativa

\begin{tabular}{c|l|c|c|c|c}
\hline $\mathbf{N}^{\mathbf{0}}$ & \multicolumn{1}{|c|}{ Questões } & Ruim & Regular & Bom & Ótimo \\
\hline Q11 & $\begin{array}{l}\text { Como você avalia trabalhar com } \\
\text { seus colegas? }\end{array}$ & - & - & $\begin{array}{c}35,5 \% \\
(05 \text { alunos })\end{array}$ & $\begin{array}{c}64,5 \% \\
(09 \text { alunos })\end{array}$ \\
\hline Q12 & $\begin{array}{l}\text { O que você acha de estudar com } \\
\text { sua equipe para resolver as } \\
\text { situações-problemas? }\end{array}$ & - & - & $\begin{array}{c}35,5 \% \\
(05 \text { alunos })\end{array}$ & $\begin{array}{c}64,5 \% \\
(09 \text { alunos })\end{array}$ \\
\hline Q13 & Como você considera seu trabalho & - & - & $28,5 \%$ & $71,5 \%(10$ \\
\hline
\end{tabular}




\begin{tabular}{c|l|c|c|c|c}
\hline & para ajudar sua equipe? & & & $(04$ alunos $)$ & alunos $)$ \\
\hline Q14 & $\begin{array}{l}\text { Como você considera o trabalho } \\
\text { da sua equipe para te ajudar? }\end{array}$ & - & - & $\begin{array}{c}35,5 \% \\
(05 \text { alunos })\end{array}$ & $\begin{array}{c}64,5 \% \\
(09 \text { alunos })\end{array}$ \\
\hline \multirow{2}{*}{ Q15 } & $\begin{array}{l}\text { Como foi sua experiência em ter } \\
\text { que fazer as atividades no } \\
\text { Minecraft com outros colegas? }\end{array}$ & - & - & $\begin{array}{c}35,5 \% \\
(05 \text { alunos })\end{array}$ & $\begin{array}{c}64,5 \% \\
(09 \text { alunos })\end{array}$ \\
\hline
\end{tabular}

Os resultados expõem a realização do trabalho em equipe durante as atividades/desafios, essa concepção promoveu a aprendizagem colaborativa, onde os alunos trabalharam e ganharam habilidades que reforçaram as relações interpessoais. Assim, as questões Q11, Q12, Q14 e Q15 apresentam resultado dividido entre duas opções, 35,5\% na opção "bom" e 64,5\% na opção "ótimo". Enquanto, Q13 apresentou o resultado dividido com as seguintes proporções, 28,5\% na opção "bom" e 71,5\% na opção "ótimo". Dessa forma, nota-se que ao trabalharmos a aprendizagem colaborativa ocorreram mais desafios, pois trabalho em grupo para os alunos do Ensino Fundamental I é realmente algo pouco empregado, daí a dificuldade de realizar as atividades estabelecidas.

\section{Conclusão e Perspectivas Futuras}

Este artigo apresentou um estudo sobre a utilização do jogo digital Minecraft com alunos do $4^{\circ}$ ano do Ensino Fundamental I em uma instituição pública, para estimular o pensamento computacional e aprendizagem colaborativa. A principal motivação do estudo é introduzir os conceitos do pensamento computacional, como abstração, algoritmo e decomposição, além de promover o ganho de habilidades interpessoais com o trabalho em equipe.

Dessa forma, o estudo aponta que o uso do jogo Minecraft pode permitir um ambiente mais atrativo aos alunos, fazendo-os trabalhar aspectos relacionados a atenção e concentração. Por meio das funcionalidades on-line que o jogo possui, os alunos puderam trabalhar em equipe e assim possibilitar a prática da relação interpessoal, uma das habilidades da aprendizagem colaborativa.

Nesse contexto, o presente estudo aponta indícios favoráveis sobre a utilização do jogo Minecraft a fim de proporcionar um ambiente de trabalho em equipe e no processo de ensino sobre os conceitos do pensamento computacional, porém faz-se necessário a continuação da pesquisa para investigar pontos que precisam ser mais debatidos e questionados, por exemplo, como abordar o conceito de algoritmo e quais novas estratégias de trabalho em equipe podem ser empregadas.

Como sugestão de trabalhos futuros, pode-se definir: (1) Produzir novas atividades/desafios que promovam o conceito algoritmo; (2) Estudar novas estratégias de trabalho em equipe; (3) Realizar um novo estudo com uma amostra maior.

\section{Agradecimentos}

A Pró-Reitoria de Extensão e Assuntos Comunitários (PROEX) da Universidade do Estado do Amazonas (UEA), a Escola Estadual Capitão General Mendonça Furtado no município de Itacoatiara-AM, por permitir a execução do experimento com os alunos e aos pais e/ou responsáveis dos participantes por autorizarem a participação dos mesmos no projeto. 
IX Congresso Brasileiro de Informática na Educação (CBIE 2020)

Anais do XXVI Workshop de Informática na Escola (WIE 2020)

\section{Referências}

Amaro, Sandra et al. (2016). Os meninos à volta do computador: a aprendizagem colaborativa na era digital. Eduser-Revista de Educação 1.1.

Blikstein, P. (2018). Maker Movement in Education: History and Prospects. In: M.J. de Vries (ed) Handbook of Education. Springer International Publishing.

de Souza, D. R. et al. (2018). Using Augmented Reality in the Development of Literacy for Students with Special Educational Needs. In 2018 XIII Latin American Conference on Learning Technologies (LACLO) (pp. 173-180). IEEE.

Dias, Natália Ferreira; Rosalen, Marilena. (2014). Minecraft: Uma Estratégia de Ensino para Aprender mais Jogando. SIED: EnPED-Simpósio Internacional de Educação a Distância e Encontro de Pesquisadores em Educação a Distância.

Ferreira, Tamara C. et al. (2019). Desenvolvimento do Pensamento Computacional na Ciência da Computação: uma Questão de Gênero?. In: Anais dos Workshops do Congresso Brasileiro de Informática na Educação. p. 945.

Fragelli, Ricardo. (2019). Método trezentos: Aprendizagem ativa e colaborativa, para além do conteúdo. Penso Editora.

Machado, J., \& Junior, A. (2019). Utilização de jogos como ferramenta para auxiliar o desenvolvimento do Pensamento Computacional: uma revisão sistemática. In Anais do Workshop de Informática na Escola (Vol. 25, No. 1, p. 217).

Nebel, Steve; Schneider, Sascha; REY, Günter Daniel. (2016). Mining learning and crafting scientific experiments: a literature review on the use of minecraft in education and research. Journal of Educational Technology \& Society, v. 19, n. 2, p. 355 .

Paiva, C. A., \& Tori, R. (2017). Jogos Digitais no Ensino: processos cognitivos, benefícios e desafios. XVI SBGames, Curitiba, novembro, 1052-1055.

Raabe, André, et al. (2018). Movimento Maker e Construcionismo na Educação Básica: Fomentando o exercício responsável da liberdade. Anais do Workshop de Informática na Escola. Vol. 24. No. 1.

Romanó, R. S. (2003). Ambiente Virtuais para a Aprendizagem Colaborativa no Ensino fundamental. III Conferência Internacional de Tecnologias de Informação $e$ Comunicação na Educação.

Santana, A. L. M., \& Martins, P. (2017). Desenvolvimento e avaliação de modificação do jogo minecraft para estimular o pensamento computacional em estudantes do ensino médio. In Anais dos Workshops do Congresso Brasileiro de Informática na Educação (Vol. 6, No. 1, p. 92).

Souza, José Klemer Crispim de. (2016). Utilização do Jogo Digital Minecraft no processo de ensino aprendizagem.

Wing, J. M. (2006). Computational thinking. Communications of the ACM, 49(3), 3335 . 